\title{
(C) OPEN ACCESS \\ A work observation study of nuclear medicine technologists: interruptions, resilience and implications for patient safety
}

\author{
George Larcos, ${ }^{1}$ Mirela Prgomet, ${ }^{2}$ Andrew Georgiou, ${ }^{2}$ \\ Johanna Westbrook ${ }^{2}$
}

'Department of Nuclear Medicine \& Ultrasound Westmead Hospital \& University of Sydney, Sydney, New South Wales, Australia

${ }^{2}$ Australian Institute of Health Innovation, Macquarie University, Sydney, New South Wales, Australia

\section{Correspondence to}

Dr George Larcos, Department of Nuclear Medicine \&

Ultrasound, Westmead Hospital \& University of Sydney, Sydney, NSW 2145, Australia; george. larcos@health.nsw.gov.au

Received 27 June 2016 Revised 15 September 2016 Accepted 16 September 2016 Published Online First

5 October 2016

\begin{abstract}
Background Errors by nuclear medicine technologists during the preparation of radiopharmaceuticals or at other times can cause patient harm and may reflect the impact of interruptions, busy work environments and deficient systems or processes. We aimed to: (a) characterise the rate and nature of interruptions technologists experience and (b) identify strategies that support safety.
\end{abstract}

Methods We performed 100 hours of observation of 11 technologists at a major public hospital and measured the proportions of time spent in eight categories of work tasks, location of task, interruption rate and type and multitasking (tasks conducted in parallel). We catalogued specific safety-oriented strategies used by technologists.

Results Technologists completed 5227 tasks and experienced 569 interruptions (mean, 4.5 times per hour; $95 \% \mathrm{Cl} 4.1$ to 4.9 ). The highest interruption rate occurred when technologists were in transit between rooms (10.3 per hour (95\% Cl 8.3 to 12.5$)$ ). Interruptions during radiopharmaceutical preparation occurred a mean of 4.4 times per hour $(95 \% \mathrm{Cl} 3.3$ to 5.6 ) Most $(n=426)$ tasks were interrupted once only and all tasks were resumed after interruption. Multitasking occurred $16.6 \%$ of the time. At least some interruptions were initiated by other technologists to convey important information and/or to render assistance. Technologists employed a variety of verbal and non-verbal strategies in all work areas (notably in the hotlab) to minimise the impact of interruptions and optimise the safe conduct of procedures. Although most were due to individual choices, some strategies reflected overt or subliminal departmental policy.

Conclusions Some interruptions appear beneficial. Technologists' self-initiated strategies to support safe work practices appear to be an important element in supporting a resilient work environment in nuclear medicine.

\section{BACKGROUND}

Healthcare personnel operate in dynamic and busy environments in which urgent and non-urgent tasks vie for attention and prioritisation. ${ }^{1}$ Multitasking and interruptions such as overhead pages, telephone calls and distractions from other staff and patients are widespread and may contribute to errors. ${ }^{2-4}$ Further, deficiencies in work systems and processes can cause unexpected delays and magnify the challenges. ${ }^{5}$ Therefore, understanding the rate and nature of interruptions that personnel experience, how everyday clinical work is delivered and the systems in which personnel operate merit additional study and research in these topics could identify other ways to improve safety.

In nuclear medicine, the maladministration of radiopharmaceuticals is an important patient safety issue because the unintended exposure to ionising radiation may be harmful. ${ }^{6}$ Research indicates that technologists are directly involved in about $70 \%$ of maladministrations, ${ }^{6}$ but there has been little evaluation regarding their work patterns, the interruptions that they experience and the environment in which tasks are undertaken. Typically, technologists prepare radiopharmaceuticals in a designated 'hot-lab' area featuring appropriately shielded workbenches, sinks, refrigeration for lyophilised products, radioactivity counters, disposal bins and other material. Procedures are mostly routine in nature and there is usually adequate notice of the type of 
study required at the start of each working day. Consequently, radiopharmaceuticals are often prepared in batches for patients having similar procedures and then dispensed into separate syringes for later use. Urgent procedures are occasionally requested, which necessitates the preparation of some radiopharmaceuticals for an individual patient at short notice. Once prepared, the same or other technologists deliver radiopharmaceuticals to injection or scanning rooms for administration to patients. Since most procedures are routine and can take several hours to complete the various components of the scan, the majority of studies commence in the morning. Usually, technologists work in teams to undertake procedures, with specific tasks allocated to different individuals; in some cases, however, a single technologist is responsible for the conduct of all tasks related to a patient's procedure. As well, two different cameras are used to study patients as part of the same procedure, necessitating coordination of staff and resources. Images are subsequently analysed, archived and presented to doctors for interpretation. Technologists have responsibility for scheduling and coordination of procedures, liaison with other health professionals, quality assurance and administrative tasks. Thus, technologists are comprehensively involved in the complete cycle of nuclear medicine procedures, working in dynamic ways with one other, as well as other clinical staff, in multiple locations within the department.

Patient safety in nuclear medicine may be enhanced by managing interruptions, since it is possible that these contribute to maladministrations, especially during vulnerable tasks such as the preparation of radiopharmaceuticals.' 'Quiet zones' and other interruption management strategies during medication preparation and administration have been trialled on some general medical wards, but the evidence of benefit is weak. ${ }^{8}$ Further, there may be undesirable consequences because some alerts or interruptions from equipment or other staff may bolster safety in certain circumstances. $^{2} 9$ Thus, more empirical evidence is needed to inform the development of quality interventions in nuclear medicine.

Incident reporting is widely used to inform quality improvement, but provides limited insights into how healthcare personnel create and maintain safety at work (as occurs the vast majority of the time). In nuclear medicine, for example, Australian Incident Registry data identify circumstances directly related to maladministrations and it is unsurprising that ensuing quality improvement strategies have sought to remedy perceived deficits in procedural compliance or training. ${ }^{6} 1011$ Concern about the narrow focus inherent in identifying what has gone wrong (as reflected in incident report data) has stimulated calls for an additional approach in patient safety to explore aspects of 'resilience' in the workplace. ${ }^{12}$ In contrast to incident reporting, assessment of resilience in the workplace proactively samples a much larger source of data and refines safety by promoting flexibility rather than compliance with protocols, guides and training. ${ }^{12} 13$ That is, understanding how nuclear medicine technologists adapt to unpredictable workloads and disruptive events and the strategies they invoke to maintain safety in dynamic environments with inherent deficiencies in equipment, systems and processes ${ }^{5}$ could lead to a better understanding of what happens when things go right. ${ }^{12}{ }^{13}$ An approach incorporating resilience could lead to novel quality improvement strategies in nuclear medicine, but this requires careful research because resilient behaviours are often implicit. ${ }^{14}$

Accordingly, the primary objectives of this work observation study of nuclear medicine technologists were to: (a) characterise their work patterns, including the rate and nature of interruptions they experience and (b) identify strategies that support safety in the workplace. A secondary objective was to use these results to suggest quality improvement strategies in nuclear medicine that may complement those derived from incident reporting. ${ }^{6} 11$

\section{MATERIALS AND METHODS}

\section{Study design and sample}

We conducted a direct observational time and motion study in the nuclear medicine department of a major public teaching hospital (975 beds) in Sydney, which performs about 5600 general nuclear medicine and positron emission tomography (PET) studies annually. The department has 11 technologists (six full-time and five part-time), three of whom are designated as 'seniors' (ie, responsible for specific administrative and supervisory roles, in addition to the tasks undertaken by the junior staff). The 11 technologists have between 1 and 23 years of experience (mean=6.6 years) post-professional development year (in Australia, technologists typically receive 3 years of university training and become registered after a further year of 'on-the-job' training). All 11 technologists were invited to participate and received information about the purpose of the study and the nature of the proposed observations. A total of 100 hours of observation were conducted between $07: 00$ and 16:30 on weekdays from October to December 2015. We allocated $50 \%$ of the observation sessions to periods in which radiopharmaceutical preparatory activities were most intense (typically, early and midmorning times). To evaluate whether there was an association between seniority and rate of interruptions, we devoted 50\% of observation sessions to the three senior technologists. To satisfy these two parameters, we determined on a weekly basis which periods to monitor. If there was more than one eligible technologist for a given period, we used a random draw to determine the individual to be observed. There was no departmental 
policy on interruptions, although the use of smartphones was discouraged except during personal times.

\section{Data collection}

One member of our team, with intimate knowledge of nuclear medicine processes, unobtrusively observed a participating technologist from several metres and collected information for periods of 30-120 min while they carried out their usual work tasks. Observational data were recorded on a handheld tablet, using the Work Observation Method By Activity Timing (WOMBAT) software program, ${ }^{15}$ adapted to a nuclear medicine environment. Eight broad categories of mutually exclusive work tasks (some with subcategories) were developed after extensive observation and pilot testing (table 1). A researcher who had extensive experience of the WOMBAT observational approach trained the observer. During pilot testing, the observer and researcher iteratively reviewed and adjusted preliminary findings to ensure that the full range of technologists' tasks was captured and appropriately categorised. The WOMBAT program has previously been shown to have high $(>85 \%)$ inter-rater reliability. ${ }^{15}$ Although we did not specifically assess reliability in this context, we used the same template and principles to assign nuclear medicine-specific tasks into the various categories for this study. Despite its potentially vulnerable nature, ${ }^{6}{ }^{11}$ we did not create a separate work category for radiopharmaceutical preparation because this task is an important element of indirect care. Nevertheless, its inclusion as a subcategory rendered sufficient transparency for us to separately determine the rate of interruptions associated with these tasks.

Recorded tasks were automatically time-stamped on data entry and the observer recorded whom the subject was with and the location where the task was performed. Interruptions and multitasking were recorded using buttons in WOMBAT and were defined as follows: an interruption occurred when a technologist ceased a current task to respond to an external stimulus; multitasking occurred when the technologist continued their current task while responding to an external stimulus, for example, preparing radiopharmaceutical while talking to a colleague. Tasks which were suspended due to interruption remain visible in WOMBAT to permit recording if the original task was resumed. This feature allows recording of the length and nature of each interruption and multitask.

Table 1 Nuclear medicine technologist task classification

\begin{tabular}{|c|c|c|}
\hline Task category & Definition & Included activities \\
\hline Direct care & Tasks directly related to patient care & $\begin{array}{l}\text { Preparing a camera or room for a scan } \\
\text { Assisting a patient before or after a procedure } \\
\text { Scanning a patient } \\
\text { Interacting with patient and/or relative }\end{array}$ \\
\hline Indirect care & Tasks indirectly related to patient care & $\begin{array}{l}\text { Review of request forms, bookings, preparation } \\
\text { requirements for tests } \\
\text { Washing hands } \\
\text { Cleaning or preparing workbenches, scan equipment and beds } \\
\text { Changing bed linen } \\
\text { Radiopharmaceutical preparation } \\
\text { Quality control } \\
\text { Analysing scan } \\
\text { Disposal and/or return of radioactive waste, paperwork }\end{array}$ \\
\hline Documentation & Data entry into computer or paperwork & $\begin{array}{l}\text { Recording doses administered, quality control results and patient } \\
\text { demographics }\end{array}$ \\
\hline $\begin{array}{l}\text { Professional } \\
\text { communication }\end{array}$ & Any work-related discussion with another staff member & $\begin{array}{l}\text { Communication on scheduling, transfers, preparation for procedures, } \\
\text { protocol to be used and handover of care } \\
\text { Includes the use of fixed or mobile phones or pages }\end{array}$ \\
\hline Social & Any social or personal activity or discussion & $\begin{array}{l}\text { Personal phone calls and discussions } \\
\text { Tea, lunch and personal breaks } \\
\text { Private reading } \\
\text { Private email or social media } \\
\text { Bathroom breaks }\end{array}$ \\
\hline $\begin{array}{l}\text { Supervision and } \\
\text { education }\end{array}$ & Any activity focused on teaching or education & $\begin{array}{l}\text { Supervision of other staff members or students } \\
\text { Mandatory health training } \\
\text { Research } \\
\text { Participating in departmental education sessions }\end{array}$ \\
\hline Administrative & $\begin{array}{l}\text { Any administrative activity not directly related to direct } \\
\text { or indirect care or documentation }\end{array}$ & $\begin{array}{l}\text { Preparing rosters } \\
\text { Purchase of supplies } \\
\text { Maintenance of equipment } \\
\text { Employment issues }\end{array}$ \\
\hline In transit & Work-related movement between rooms or tasks & $\begin{array}{l}\text { Includes movement between scanning rooms, movement outside the } \\
\text { department to visit patients on wards }\end{array}$ \\
\hline
\end{tabular}


In addition to the structured WOMBAT data collection, we employed an iterative process to develop a list of strategies that technologists used to uphold safety. ${ }^{12} 13$ The observer used his knowledge of nuclear medicine processes to identify potentially eligible strategies across the spectrum of tasks and in all departmental areas. For this part of the study, we did not specifically focus on the level of the seniority of the participant. Rather, the observer documented any behaviour, for example, placing sticky notes on a radiopharmaceutical phial or choosing not to interrupt a colleague, which prima facie contributed to maintaining or creating safe working situations. Strategies could pertain to an individual's behaviour or reflect the use of a tool or an agreed strategy used by the entire cohort. Following observation sessions, the observer then conferred with the participating technologist to ask about the observed strategies and only those behaviours that had a confirmed safety intent were retained. Subsequent periods of unstructured observation and discussion at other times with the same or other participants were used to expand the list.

Once the list of strategies with a confirmed safety intent had been compiled, the project team then discussed and reached agreement about the classification of these strategies. For this purpose, we used a previous report ${ }^{16}$ to classify each recorded strategy according to four categories. The categories, with descriptions in parentheses, are as follows: 'responsiveness' (reacting effectively when a situation changes); 'attentiveness (taking appropriate action considering the situation at hand); 'anticipation' (proactively making a decision or taking a course of action that has an expected consequence in a given situation) and 'past experience' (drawing on existing knowledge to influence the sequence and nature of work activities).

The research was approved by the hospital and university research ethics committees and written informed consent was obtained from all 11 technologists, all of whom participated in the study.

\section{Data analysis}

Descriptive analyses were performed for: the total number of tasks; the total time that tasks were 'active' in each category (ie, only tasks that were being actively performed, rather than paused by interruptions); the proportion of time spent on various tasks at different times during the day and rates of interruptions and multitasking. In addition, we used linear regression to assess the relationship between the interruption rate and the number of tasks, hours of observation and number of nuclear medicine and PET procedures for that day. We also determined whether any interrupted tasks were not resumed.

Data were analysed in Microsoft Excel (2016) with pivot tables and 95\% CIs were calculated using a Poisson distribution. Student's t-test was used to compare the rate of interruptions experienced by senior and junior technologists.

\section{RESULTS}

\section{Task times, interruptions and multitasking}

During the 100 hours of observation, 5227 tasks were observed. The task-specific distribution of technologists' time is shown in table 2. Direct care tasks consumed the highest proportion of technologists' time (34.6\%), although there was a variation during the day. For example, direct care tasks represented about $40 \%$ of all tasks at 09:00, increasing slightly in proportion at 14:00, from which time their proportion tapered to about $20 \%$ by the end of the working day. Indirect care tasks were the next most frequent in number $(28.8 \%)$, but these were most predominant between 07:30 and 09:00, when technologists were preparing for the various procedures scheduled for the day. Supervision, social and administrative tasks also displayed distinct variations according to the time of day. The mean time allocated to each of the eight work categories from $07: 00$ to $16: 30$ is shown in figure 1.

There were 116.6 task hours during the 100 hours of observation, demonstrating that technologists multitasked $16.6 \%$ of their time. The highest rate of

Table 2 Distribution of task times, multitasking and interruption rates

\begin{tabular}{llllll}
\hline Task category & $\begin{array}{l}\text { Number of tasks } \\
(\%)\end{array}$ & $\begin{array}{l}\text { Task time } \\
\text { (hours) }\end{array}$ & $\begin{array}{l}\text { Mean task } \\
\text { time }(\mathrm{s})\end{array}$ & $\begin{array}{l}\text { \% task time spent multitasking } \\
(95 \% \mathrm{Cl})\end{array}$ & $\begin{array}{l}\text { Interruption rate per hour, } \\
(95 \% \mathrm{Cl})\end{array}$ \\
\hline Direct care & $1102(21.1)$ & 34.6 & 112 & $42.8(26.3$ to 59.3$)$ & $4.4(3.8$ to 5.1$)$ \\
Indirect care & $1221(23.4)$ & 28.8 & 85 & $20.0(5.4$ to 34.6$)$ & $6.0(5.2$ to 6.9$)$ \\
Documentation & $224(4.3)$ & 3.8 & 61 & $12.6(0$ to 46$)$ & $8.4(6.1$ to 11.5$)$ \\
In transit & $814(15.6)$ & 7.3 & 32 & $9.9(0$ to 31.6$)$ & $10.3(8.3$ to 12.5$)$ \\
$\begin{array}{l}\text { Professional } \\
\text { communication }\end{array}$ & $1478(28.3)$ & 17.7 & 43 & $42.2(19.2$ to 65.2$)$ & $3.5(2.7$ to 4.4$)$ \\
Social & $196(3.7)$ & 12.0 & 220 & $7.2(0$ to 21.8$)$ & $1.4(0.9$ to 2.2$)$ \\
$\begin{array}{l}\text { Supervision or } \\
\text { education }\end{array}$ & $162(3.1)$ & 9.2 & 204 & $41.6(9.8$ to 73.5$)$ & $4.6(3.4$ to 6.0$)$ \\
Administrative & $30(0.6)$ & 3.2 & 384 & $7.8(0$ to 37.2$)$ & $4.7(2.9$ to 7.5$)$
\end{tabular}

Task times do not add to 100 hours because some tasks were undertaken simultaneously (ie, when multitasking). 


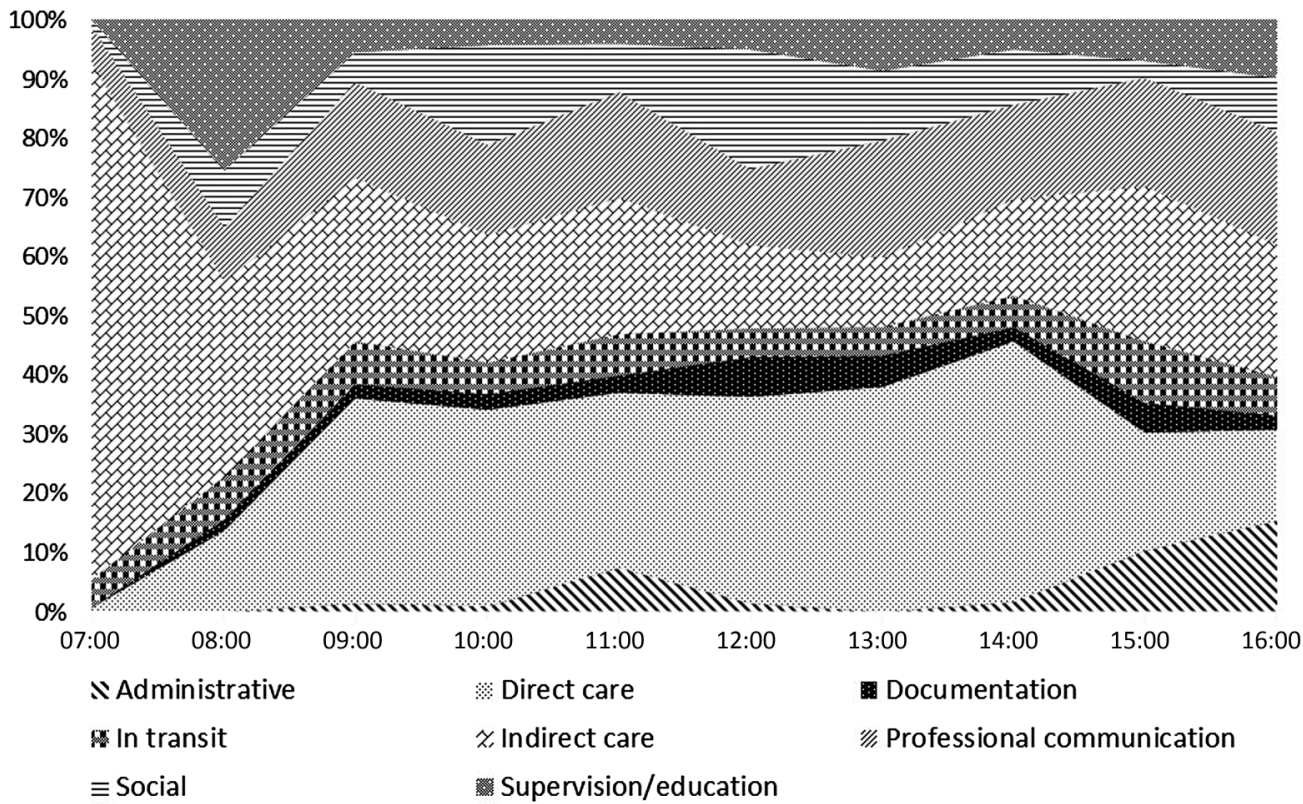

Figure 1 Time allocated to different tasks by nuclear medicine technologists from 07:00 to 16:00.

multitasking occurred during direct care or when the technologist was supervising or educating another technologist $(42.8 \%$ and $42.2 \%$, respectively). The multitasking rate during indirect care was 20\% (95\% CI $5.4 \%$ to $30.6 \%$ ). A common example was professional communication occurring while preparing a radiopharmaceutical. Multitasking mostly occurred at one point in time only; however, some individual tasks of longer duration featured several instances of multitasking (up to 13 separate times). Multitasking never involved more than two tasks simultaneously. The mean duration of multitasking was $60 \mathrm{~s}$ (range, 1-647 s).

Five hundred and sixty-nine tasks $(10.9 \%$ of the total) were interrupted, with the highest rate occurring when a technologist was in transit (10.3 interruptions/hour). The overall interruption rate was 4.5 / hour (95\% CI 4.1 to 4.9 ) across all tasks (table 2).

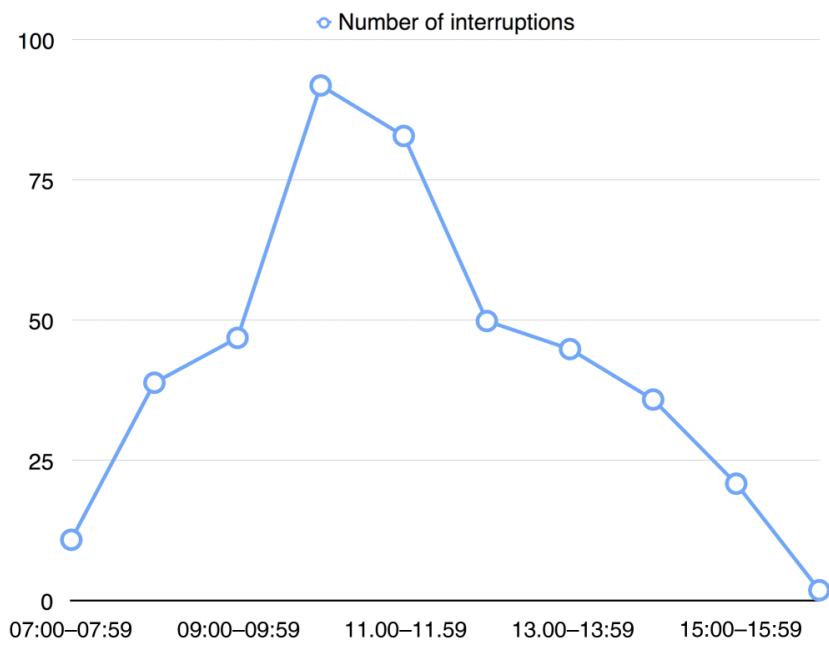

Figure 2 Number of interruptions over a working day.
When tasks were interrupted, most $(n=426$; $74.9 \%)$ were only interrupted once, but 143 tasks (25.1\%) were interrupted on two or more occasions, including one that was interrupted 10 times. Most interruptions $(\mathrm{n}=331 ; 58.2 \%)$ were experienced in scan rooms. The mean time to return to the primary task was $75 \mathrm{~s}$ (range: 3-1289 s). All tasks were resumed after being interrupted. Interruptions were most common during mid to late mornings (figure 2). Indirect care tasks were interrupted 6 times/hour (95\% CI 5.2 to 6.9 ), but the subcategory of radiopharmaceutical preparatory tasks had a mean interruption rate of 4.4 interruptions/hour $(95 \%$ CI 3.3 to 5.6). Senior and junior nuclear medicine technologists experienced 5.5 and 4.3 interruptions/hour, respectively $(p=0.91)$. The interruption rate per hour was not related to the number of procedures, observed tasks or hours of observation for that day $\left(r^{2}=0.11\right.$, $\mathrm{p}=0.67$, degrees of freedom $=3$ ).

\section{Strategies used by technologists to support safe work}

The majority of safe work behaviours were noted in the hot-lab area, with some consistent examples including: (a) the use of bar-coding technology to label all syringes with the correct patient name, radiopharmaceutical type and radioactivity, (b) manual colour coding of the daily patient schedule according to the radiopharmaceutical type, (c) quality assurance summaries that were prominently displayed as visual aids in the hot-lab and (d) the early arrival of hot-lab staff for duty. Behaviours involving communication and/or handover between staff were most common and included both verbal and non-verbal modes. The latter comprised sticky notes, syringe labels and whiteboards and again mainly featured in the hot-lab area. Some visual aids, such as the manual colour coding of patient 
lists for batch radiopharmaceutical preparation, acted as an aide-memoire for individuals, rather than a communication mechanism between technologists. Further, some strategies reflected decisions made by individual technologists at a particular time (eg, not interrupting a colleague or deferring taking a break), although others (such as the implementation of bar-coding for syringes, the use of a whiteboard and rostering a single technologist to therapeutic nuclear medicine) reflected a deliberate decision by the cohort and its managers to uphold safe work practices. We noted that some interruptions among technologists were designed to facilitate technical information about patients or procedures or to render assistance in the completion of certain tasks. Among resilient behaviours, responsiveness, attentiveness, anticipation and past experience were identified in approximately equal numbers, although some could be classified using more than one characteristic (table 3).

\section{DISCUSSION}

Our study demonstrated that nuclear technologists experienced an interruption on average every $13.3 \mathrm{~min}$ that divert their attention for around $75 \mathrm{~s}$ before returning to their primary task. Technologists experienced an interruption every $13.6 \mathrm{~min}$ while preparing radiopharmaceuticals, which is the most safety critical element of their work. Some interruptions were initiated by other technologists in order to convey important information to one another, facilitate the optimum conduct of procedures and render assistance in the completion of tasks. Technologists employed various strategies, which were mostly self-initiated, to safeguard tasks that are perceived as vulnerable.

The average interruption rate in nuclear medicine is similar to that reported for doctors working in general community hospital settings ${ }^{3}$ and slightly less than reported for Australian doctors in intensive care units and emergency departments. ${ }^{17} 18$ In a previous review, interruption management strategies, including the wearing of manual vests, the use of prominently displayed signs or lanyards discouraging interruptions, checklists and diversion techniques, showed that the evidence for benefit was limited. ${ }^{8}$ Interruption management strategies may have implications in nuclear medicine because errors during radiopharmaceutical preparation and administration contribute to the majority of maladministrations. ${ }^{6} 11$ Our data show that technologists preparing radiopharmaceuticals were interrupted on average 4.4 times/hour; this is slightly less than the overall average for the department and much less than in other areas, such as in scanning rooms or while technologists are in transit. Thus, the formal institution of quiet zones in the hot-lab area, even for busier times of the day, may provide limited benefit. Further, this type of interruption management strategy could be counterproductive because we witnessed examples of other technologists occasionally interrupting the observed individual to convey key technical details about specific patients or procedures or to render assistance for tasks.

Multitasking was evident with all task categories, with the highest rates noted during direct care, professional communication and while supervising other colleagues. The discrepancy in multitasking rates between task categories probably reflects differences in the nature of the primary task, its perceived vulnerability to failure if paused, interruption rate, proximity of other health personnel and patients and the configuration of the room in which the task is being conducted. While multitasking is thought to impose a cognitive load and may be deleterious to the primary task, ${ }^{219}$ the nature and timing of the interaction, the type of primary task being conducted and characteristics of the persons involved are important contextual factors. ${ }^{20}$ As an example, multitasking in the hot-lab commonly involved the participating technologist actively mixing compounds or measuring radioactivity while conferring with a colleague about a specific patient or procedure. This type of multitask permits the transfer of important information, without the technologist having to pause at critical times during radiopharmaceutical preparation. Therefore, multitasking may foster efficiency in certain circumstances. This is consistent with a previous report ${ }^{21}$ and suggests that restrictions on multitasking, even during potentially vulnerable tasks such as radiopharmaceutical preparation may have unwanted consequences.

Our results showed that technologists often employed various strategies to buttress the safe conduct of procedures in specific circumstances and across all work areas. Some strategies (such as arriving early to commence radiopharmaceutical preparatory tasks before peak interruptions were likely to occur or avoiding interrupting colleagues at inopportune times) were explicitly focused on avoiding interruptions, whereas others (such as prominently displayed summaries of quality assurance procedures in the hot-lab, appointment of specific technologists to undertake therapeutic procedures from start to finish and the use of sticky notes on request forms and prepared radiopharmaceutical syringes to help with information transfer) were not. Although many strategies reflected individual choices in relation to a particular task, these tended to be observed in most or all of the technologist cohorts, despite the lack of a formal policy. We suggest that this indicates the existence of an informal communication network in which potential 'process failures' are recognised and solutions implemented by the technologists themselves. This type of approach is consistent with 'second-order' problem solving as reported by Tucker and Edmondson. ${ }^{22}$ However, one important difference from their problem-solving model is that, with a few exceptions, most strategies in our study were implemented without specific managerial input. 


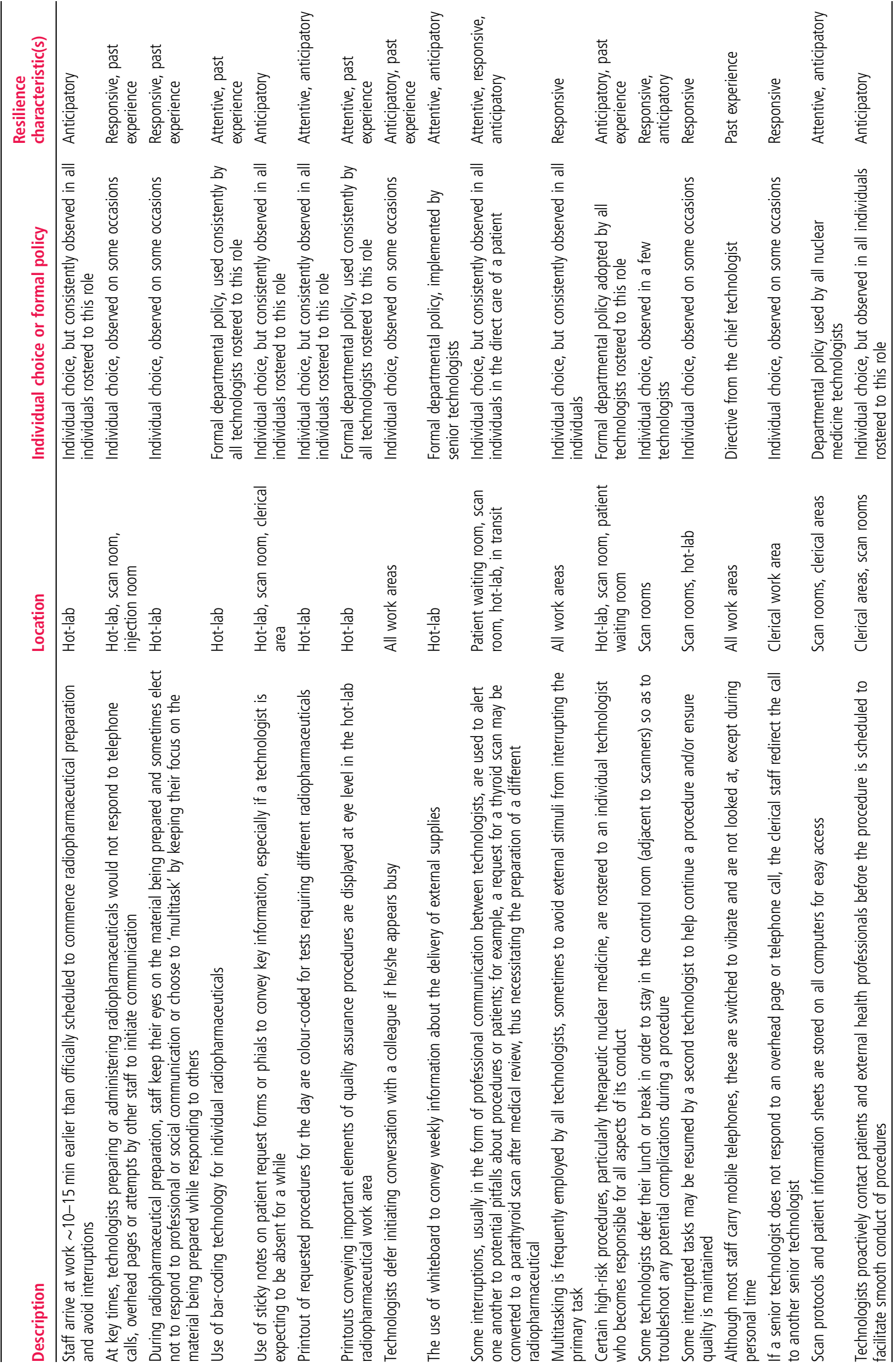


The identification of resilient strategies among technologists has several implications for patient safety in nuclear medicine. The technologists were found to implicitly uphold safety in broad ways and the type of resilient strategies that are identified may provide important clues about underlying organisational deficiencies, including inadequate staffing, faulty equipment, poor workplace design and miscommunication among staff. ${ }^{5} 22$ Promotion of resilience among technologists should be accompanied by thoughtful analysis and correction of any operational vulnerabilities. For example, changes in quality control requirements from time to time, as well as the exacting nature of radiochemistry and limited shelf-life of various products have been shown to contribute to certain types of maladministrations. ${ }^{6}$ Thus, coordination and collaboration among technologists are critical towards the timely delivery and safe preparation of various radiopharmaceuticals. The use of a whiteboard in the hot-lab is an obvious strategy in our department, but in other facilities could signal the need to modify technologist rostering or how tasks are allocated. Radiation protection and patient safety initiatives in nuclear medicine in Australia have been developed almost exclusively from the narrow domain of a statutory incident reporting system. ${ }^{6} 71011$ Our findings suggest that looking at interventions which support and enable resilient behaviours could provide additional value in improving safety in nuclear medicine.

Our research has several potential limitations. First, errors in the preparation of radiopharmaceuticals represent the main type of maladministrations and can occur in various settings, including from commercial manufacturers. ${ }^{6} 711$ Work practices in commercial entities are likely significantly different from those in clinical nuclear medicine facilities. We do not exclude the possibility of benefit from interruption management in commercial entities. Second, we highlighted certain strategies among technologists that have characteristics of resilience. ${ }^{16}$ However, refining the approach would require assessing not just whether a particular strategy can be identified in any individual technologist, but how consistently these are applied from day to day. As well, the interobserver reproducibility of the classification system we used is undefined and is worthy of testing in future studies. Third, our data derive from a single institution, but it is one of the largest in the country. Nuclear medicine practices likely vary, at least subtly, between facilities. The rate of interruptions experienced by nuclear medicine technologists at other facilities may differ. Finally, it is possible that participating technologists may have subtly altered or improved their work habits because they knew that they were being observed. We tried to limit this effect by spending many hours in pilot testing, thus allowing technologists to become familiar with the nature of the study. Further, we conducted the research over 3 months and recorded technologists' behaviour on multiple occasions at different times of the day, which minimised the likelihood for significant persistent changes in behaviours.

In summary, nuclear medicine technologists experience about 4.5 interruptions/hour, mainly in work areas and on tasks not directly related to radiopharmaceutical preparation and administration. Further, some interruptions are beneficial and thus, controlling interruptions per se may be counterproductive. Technologists employ various strategies that uphold safety, some of which are not specifically related to interruptions. It is possible to identify resilient behaviours among technologists and this information might aid the assessment of individual incidents, as well as contribute to the identification of new interventions which promote patient safety in nuclear medicine.

Acknowledgements We thank Helen Larcos and Scott Walter for their assistance with the portrayal and analysis of data; and nuclear medicine technologists at our institution for their willingness to participate in this study.

Competing interests None declared.

Ethics approval Sydney West Local Health District and Macquarie University.

Provenance and peer review Not commissioned; externally peer reviewed.

Data sharing statement Original data are stored at the Australian Institute of Health Innovation (Macquarie University, Sydney, Australia) and can only be accessed by the research team members.

Open Access This is an Open Access article distributed in accordance with the Creative Commons Attribution Non Commercial (CC BY-NC 4.0) license, which permits others to distribute, remix, adapt, build upon this work noncommercially, and license their derivative works on different terms, provided the original work is properly cited and the use is non-commercial. See: http://creativecommons.org/licenses/by$\mathrm{nc} / 4.0 /$

\section{REFERENCES}

1 Walter SR, Li L, Dunsmuir WTM, et al. Managing competing demands through task-switching and multitasking: a multi-setting observational study of 200 clinicians over 1000 hours. BMJ Qual Saf 2014;23:231-41.

2 Rivera-Rodriguez AJ, Karsh BT. Interruptions and distractions in healthcare: review and reappraisal. Qual Saf Health Care 2010;19:304-12.

3 Weigl M, Müller A, Vincent C, et al. The association of workflow interruptions and hospital doctors' workload: a prospective observational study. BMJ Qual Saf 2012;21: 399-407.

4 Westbrook JI, Woods A, Rob MI, et al. Association of interruptions with an increased risk and severity of medication administration errors. Arch Intern Med 2010;170:683-90.

5 Tucker AL, Singer SJ, Hayes JE, et al. Front-line perspectives on opportunities for improving the safety and efficiency of hospital work systems. Health Services Res 2008;43:1807-29.

6 Larcos GS, Collins LT, Georgiou A, et al. Maladministrations in nuclear medicine: revelations from The Australian Radiation Incident Register. Med J Aust 2014;200:37-40.

7 Yenson T, Larcos G, Collins LT. Radiopharmaceutical maladministrations in New South Wales. Nucl Med Commun 2005;26:1037-41. 
8 Raban MZ, Westbrook JI. Are interventions to reduce interruptions and errors during medication administration effective? A systematic review. BMJ Qual Saf 2014;23:414-21.

9 Grundgeiger T, Sanderson P. Interruptions in healthcare: theoretical views. Int J Med Inform 2009;78:293-307.

10 Smart RC. Radiation protection in Australia: a thirty year perspective. Aust Phys Eng Sci Med 2007;30:155-9.

11 Larcos G, Collins LT, Georgiou A, et al. Nuclear medicine incident reporting in Australia: control charts and notification rates inform quality improvement. Int Med J 2015;45:609-17.

12 Hollnagel E. Is safety a subject for science? Saf Sci 2014;67:21-4.

13 Keam S. Embracing the unexpected: resilience engineering in Australian healthcare. http://racma.edu.au/index.php? option $=$ com_content $\&$ view $=$ article $\& i d=676$; embracing-theunexpected-resilience-engineering-in-australianhealthcare\&catid =141; the-quarterly-2014\&Itemid =398 (accessed 11 Sep 2016).

14 Furniss D, Back J, Blandford A, et al. A resilience markers framework for small teams. Reliab Eng Syst Safe 2011;96:2-10.

15 Westbrook JI, Ampt A. Design, application and testing of the work observation method by activity timing (WOMBAT) to measure clinicians' patterns of work and communication. Int J Med Inform 2009;78S:S25-33.
16 Lundberg J, Rollenhagen C, Hollnagel E. What-you-look-foris-what-you-find- the consequences of underlying accident models in eight accident investigation manuals. Saf Sci 2009;47:1297-311.

17 Li L, Hains I, Hordern T, et al. What do ICU doctors do? A multisite time and motion study of the clinical work pattern of registrars. Crit Care Resusc 2015;17:159-66.

18 Westbrook JI, Coiera E, Dunsmuir WTM, et al. The impact of interruptions on clinical task completion. Qual Saf Health Care 2010;19:284-9.

19 Laxmisan A, Hakimzada F, Sayan OR, et al. The multitasking clinician: decision-making and cognitive demand during and after team handoffs in emergency care. Int J Med Inform 2007;76:801-11.

20 Walter SR, Dunsmuir WTM, Westbrook JI. Studying interruptions and multitasking in situ: the untapped potential of quantitative observational studies. Int J Hum Comput Stud 2015;79:118-25.

21 Weigl M, Müller A, Sevdalis N, et al. Relationships of multitasking, physicians' strain and performance: an observational study in ward physicians. J Patient Saf 2013;9:18-23.

22 Tucker AL, Edmondson AC. Why hospitals don't learn from failures: organizational and psychological dynamics that inhibit system changes. Cal Manag Rev 2003;45:55-72. 